\title{
Role of Endoscopic Ultrasound-Fine Needle Aspiration in Management of Submucosal Lesions (SMLs) of GIT and Significant Predictors of Malignancy of GIST Lesions
}

\author{
Shimaa Hassan Mahmoud Kaheil*1, Walaa Fahmey El-Baz², Eman Abd Rabo Abd El Rahman², \\ Hayam Hamza Mansour ${ }^{2}$, Ahmed Sadik Abd El Fattah ${ }^{3}$, Hussein Hassan Okasha ${ }^{4}$ \\ ${ }^{1}$ Internal Medicine, Armed Forced Hospitals, ${ }^{2}$ Department of Internal Medicine, \\ Faculty of Medicine (for Girls), Al-Azhar University, ${ }^{3}$ Department of Gastroenterology \& Hepatology, \\ Teodor Bilharz Research Institute (TBRI), \\ ${ }^{4}$ Department of Internal Medicine, Gastroenterology \& Hepatology, Faculty of Medicine Cairo University \\ *Corresponding author: Shimaa Hassan Mahmoud Kaheil, Mobile: (+20) 1068796618, \\ E-Mail: drshimaahassan@yahoo.com
}

\begin{abstract}
Background: Submucosal lesion is a mass or bulge covered by normal-appearing mucosa identified during standard endoscopy. Endoscopic Ultrasound (EUS) allows precise differentiation of the individual layers of the gastrointestinal (GI) tract. Endoscopic Ultrasound-Fine Needle Aspiration (EUS-FNA) permits safe and accurate sampling of submucosal lesions (SMLs) for further histopathology. Gastrointestinal stromal tumors are the commonest mesenchymal neoplasms of the GI tract. They should be stratified by malignant potential according to tumor size, location, and mitotic count.

Objectives: The aim of work was to evaluate the role of endoscopic ultrasound with EUS-FNA in management of submucosal gastrointestinal lesions, with special concern about gastrointestinal stromal tumors (GISTs) lesions and the criteria highly associated with malignant nature.

Patients and methods: This multi-center prospective study included a total of 150 patients with gastrointestinal submucosal lesions, conducted to evaluate EUS and EUS-FNA as diagnostic tools of submucosal lesions, including 68 GIST lesions. All patients underwent conventional endoscopy, EUS-FNA and histopathological examination of the samples obtained in Theodor Bilharz Research Institute, Cairo University Hospital and Kobry El Qubba Military Hospital from 2015 to 2017.

Results: There were 150 patients with submucosal GI lesions, including 93(62\%) males and 57(38\%) females, with the mean age of $52 \pm 11.9$ years. Presentations included dyspepsia 73(48.7\%), asymptomatic SMLs 31(20.7\%). The lesions were mainly gastric 102(68\%). Final diagnoses were GIST 68 (45.3\%), lipoma 11(7.3\%), leiomyoma $9(6 \%)$ and extramural lesions 7(4.7\%). There were 68 patients with GIST lesions, including $43(63.2 \%)$ males and 25(36.8\%) females, with the mean age of 54 \pm 10.3 years. Presentations included dyspepsia 41(63.2\%), asymptomatic SMLs 16(23.5\%). The lesions were mainly gastric 57(83.8\%). Sensitivity and specificity were $88.6 \%$ and $100 \%$ of EUS-FNA as diagnostic tools for GIST lesions respectively. (PPV) and (NPV) were $100 \%$ and $82.8 \%$ respectively.

Conclusion: It could be concluded that EUS and EUS-FNA were highly significant methods in diagnosis of GIST lesions in relation to final histopathology.

Keywords: Endoscopic-Ultrasound-guided Fine-Needle Aspiration (EUS-FNA), submucosal lesions, GIST.

INTRODUCTION

Submucosal lesions (SMLs) are abnormalities within the gastrointestinal (GI) tract that are deep to the epithelial layer with typically normal surface features on routine endoscopy. A vast majority of SMLs is asymptomatic and incidentally discovered. Submucosal lesions while uncommon are often difficult to characterize without endoscopic ultrasound (EUS) ${ }^{(\mathbf{1})}$.

Submucosal lesions include gastrointestinal stromal tumors (GIST), lipomas leiomyomas, carcinoid tumors, and hemangiomas ${ }^{(2)}$. EUS is a helpful and sensitive method in providing information aiding in the diagnosis and prognosis of submucosal lesions in general. It can accurately differentiate between a true intramural and an

extramural lesion compressing the wall, which is difficult to determine by regular endoscopy alone ${ }^{(3)}$.

Moreover, EUS accurately defines the size, margins, vascularity, layer of origin, and the specific echogenicity of the lesion which will help in identifying malignant or high risk lesions, and will also guide to the specific diagnosis in most of the cases. $^{3}$ The combination of EUS and FNA allows cytologic evaluation of SMLs, particularly GI stromal tumors (GISTs), with studies reporting accuracies of $80 \%$ to $91 \%{ }^{(4)}$.

Endoscopic ultrasound (EUS) was first introduced into clinical practice in the 1980s and EUS has evolved from diagnostic imaging and tissue acquisition to EUS-guided interventions ${ }^{(5)}$.
\end{abstract}


Endoscopic ultrasound (EUS) encounters both endoscopic visualization and high-frequency ultrasound (US), thus the unique advantage over traditional endoscopy. The ability to image the wall of the gastrointestinal tract as a series of definable layers corresponding to histology, rather than as a single entity, and direct imaging of the surrounding organs and tissue are the basis for most indications for EUS ${ }^{(\boldsymbol{6})}$.

Endoscopic ultrasound (EUS) has been adopted for pancreatic lesions, gastrointestinal and perigastrointestinal lesions, such as gastrointestinal cancers, gastrointestinal stromal tumors (GISTs), and abdominal and mediastinal lymphadenopathy (7).

EUS-FNA is the most widely used method for obtaining tissue from SMLs. However, the diagnostic accuracy of EUS-FNA ranges widely from $46 \%$ to $93 \%$ in the evaluation of GI stromal tumors ${ }^{(8)}$.

One proposed management strategy for gastric GI stromal tumors $<2 \mathrm{~cm}$ in size is surgical resection for lesions with high-risk EUS features and EUS surveillance at 6- month to 12 -month intervals for those without these features ${ }^{(9,10)}$.

submucosal gastrointestinal lesions can be diagnosed through invasive techniques such as endoscopic mucosal resection, or surgical resection (10).

The aim of the current work was to evaluate the significance of endoscopic ultrasound with fine needle aspiration as diagnostic tools of submucosal gastrointestinal lesions in relation to final histopathological diagnosis which is considered the ' 'gold standard'.

\section{PATIENTS AND METHODS}

This multi-center prospective study included a total of 150 patients with gastrointestinal submucosal lesions, attending at Theodor Bilharz Research Institute, Cairo University Hospital and Kobry El Qubba Military Hospital. This study was conducted between 2015 to 2017.

\section{Ethical approval:}

Approval of the ethical committee was obtained.

Patients included 93(62\%) males and 57(38\%) females, with the mean age of $52 \pm 11.9$ years. Presentations included mainly dyspepsia 73(48.7\%), asymptomatic SMLs 31(20.7\%). All patients underwent conventional endoscopy, EUSFNA and histopathological examination of the samples obtained. Endoscopic ultrasound was performed after explaining the procedure to the patient and informed consent was obtained.

\section{Inclusion criteria}

Patients with GI wall masses referred for further evaluation with EUS-FNA.

\section{Exclusion criteria}

1- Sever coagulopathy (PC $<60 \%$ or platelets $<$ $80,000 / \mathrm{mm} 3$ ).

2- Comorbid conditions that prevent deep or conscious sedation.

3- The presence of an intervening vessel between the lumen and the target lesion (excluded by Doppler performed before FNA)

All patients were subjected to;

- Complete medical history.

- Complete clinical examination.

- Laboratory tests including complete blood count (CBC), coagulation profile, liver and renal function tests, and tumor markers if needed.

- Abdominal ultrasound.

- The procedure was done under deep sedation with intra-venous Propofol. An EUS linear array machine was used (Pentax EG-3830UT and EG-3870UTK Echo-endoscope, HOYA Corporation, PENTAX Life care Division, Showanomori Technology Center, Tokyo, Japan) connected to a Hitachi EUB7000 and Avius machines ultrasound unit (Hitachi Medical System, Tokyo, Japan).

- The target lesions were initially identified and their detailed endosonographic features were assessed, including location, size and echotexture.

- EUS-FNA was carried out using a 22 and 19 gauge needles passing through the esophageal, gastric, duodenal, or colonic walls (Echotip®; WilsonCook, Winston Salem, NC).

- Onsite cytopathological examination was available in $3(4.4 \%)$ GIST patients. Slides were dried and then fixed with $95 \%$ alcohol and formalin block were used in all cases.

- All patients were kept under observation after the procedure, with no major complications were encountered.

The protocol was approved by the ethics committee of Al-Azhar University.

\section{Statistical Analysis}

All patients' data were tabulated using Excel 2010. Data were processed by Statistical Package for Social Sciences version 20 (IBM Corp.;

Armonk, NY, USA) for Windows.

All qualitative data were analyzed by chi-square test or Fischer's exact test when appropriate. The chisquare test was used to calculate Pearson's chisquare and its p-value when both variables were quantitative. Sensitivity, specificity, positive 
predictive value (PPV), and negative predictive value (NPV) were calculated.

\section{RESULTS}

This prospective study was conducted on 150 patients with submucosal GI lesions, including 93(62\%) males and 57(38\%) females, with the mean age of $52 \pm 11.9$ years. Clinical presentation included dyspepsia 73(48.7\%), asymptomatic SMLs 31(20.7\%). The lesions were mainly gastric 102 (68\%). Diagnoses were GIST 68(45.3\%), lipoma $11(7.3 \%)$, leiomyoma $9(6 \%)$ and extramural lesions $7(4.7 \%)$.

The most common lesion encountered was GIST $68(45.3 \%)$ patients were diagnosed by final histopathology; there were $43(63.2 \%)$ males and 25 $(36.8 \%)$ females. Their ages ranged from 30 years to 75 years, with the mean age of $(54 \pm 10.30)$ (Table $1)$.

As regarding the clinical presentation of GIST lesions, 41(60.3\%) patients were presented with dyspepsia, $16(23.5 \%)$ with submucosal lesions accidentally discovered during GI endoscopy for unrelated etiology, and $11(16.2 \%)$ with GI bleeding. (Table 1) (Fig.1).

The most common site was gastric $57(83.8 \%)$, esophageal $4(5.9 \%)$, rectal $3(4.4 \%)$, gastroesophageal junction 2 (2.9\%) and duodenal 2 (2.9 \%) (Fig.2).

Also, most of the gastric lesions $57(83.8 \%)$ were $27(47.3 \%)$ in the body, $21(36.8 \%)$ in the fundus, $7(12.3 \%)$ in the antrum and $2(3.5 \%)$ in the cardia.
According to the layer of origin of GIST lesions, $13(19.1 \%)$ cases involved the second GIT wall layer (muscularis mucosae), 5 (7.4\%) involved the third layer (submucosa), $46(67.6 \%)$ involved the 4th layer (muscularis propria), and $4(5.9 \%)$ involved all the wall layers (Table 2) (Fig.3)

Also, 36 (52.9\%) were homogenous texture and $32(47.1 \%)$ heterogenous texture, $98.5 \% 67$ were hypoechoic, and only one case (1.5\%) was isoechoic (Table 2)

Onsite histopathological examination was performed only in three $(4.4 \%)$ cases. (Table 2 )

The GIST lesions were classified according to maximum diameter into three groups:

- $7(10.3 \%)$ cases were $\leq 2 \mathrm{~cm}$

- $37(54.4 \%)$ cases were $(>2-\leq 5) \mathrm{cm}$

- $24(35.3 \%)$ cases were $>5 \mathrm{~cm}$ in

Table (1): Demographic data of patients and presentation of GIST cases

\begin{tabular}{|l|l|c|}
\hline \multicolumn{2}{|l|}{ GIST } & No. $=68$ \\
\hline \multirow{2}{*}{ Age (years) } & Mean \pm SD & $53.75 \pm 10.30$ \\
\cline { 2 - 3 } & Range & $30-75$ \\
\hline \multirow{4}{*}{ Gender } & Female & $25(36.8 \%)$ \\
\cline { 2 - 3 } & Male & $43(63.2 \%)$ \\
\hline & Dyspepsia & $41(60.3 \%)$ \\
\cline { 2 - 3 } & $\begin{array}{l}\text { Asymptomatic } \\
\text { submucosal } \\
\text { lesion }\end{array}$ & $\mathbf{1 6}(23.5 \%)$ \\
\cline { 2 - 3 } & Bleeding & $11(16.2 \%)$ \\
\hline
\end{tabular}

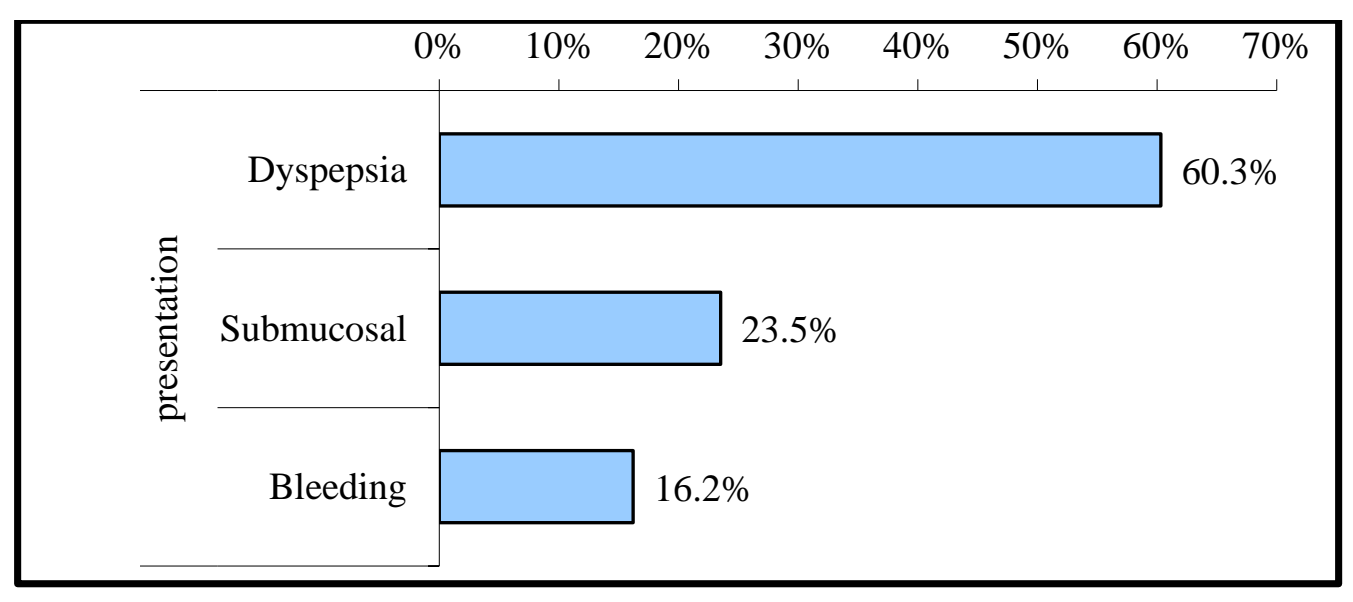

Fig. (1): Clinical presentation of GIST lesions 


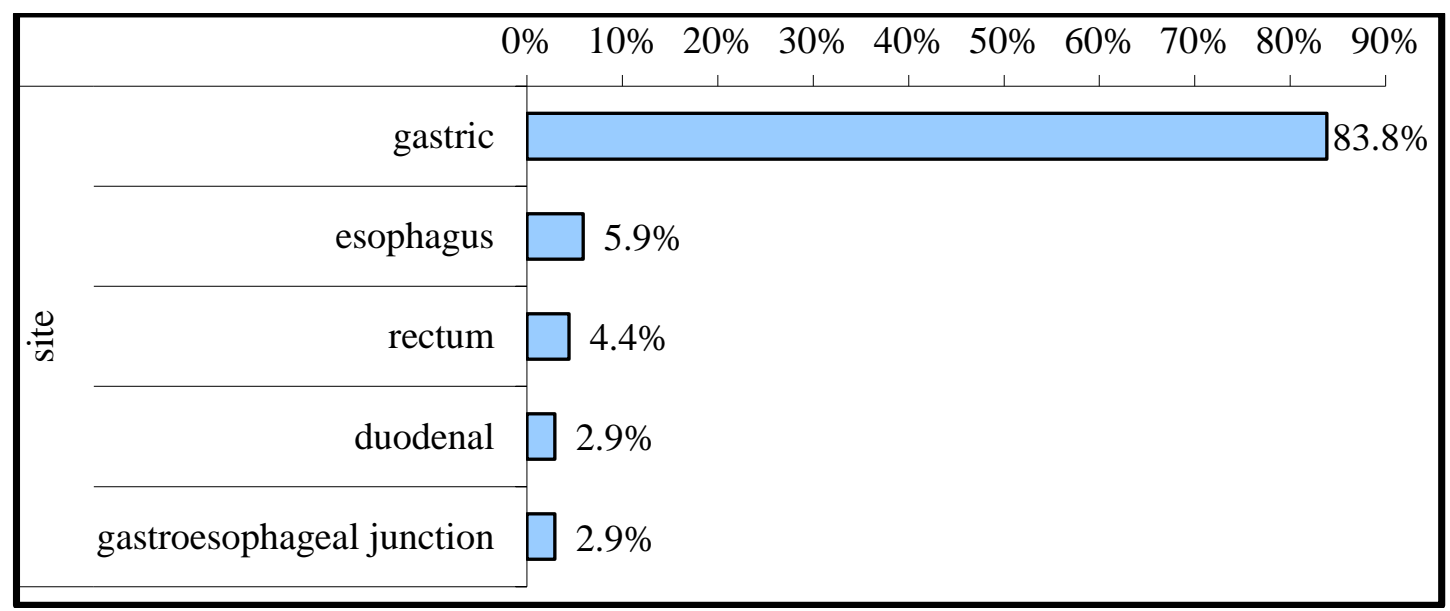

Fig. (2): Site of GIST lesions

Table (2): layer of origin, texture, echogenicity and onsite histopathological examination of GIST lesions

\begin{tabular}{|l|l|l|l|}
\hline \multicolumn{2}{|l|}{ GIST } & No. & $\%$ \\
\hline \multirow{4}{*}{ Layer } & $2^{\text {nd }}($ muscularis mucosae) & 13 & $19.1 \%$ \\
& $3^{\text {rd }}$ (submucosa) & 5 & $7.4 \%$ \\
& $4^{\text {th }}($ muscularis propria) & 46 & $67.6 \%$ \\
& All & 4 & $5.9 \%$ \\
\hline \multirow{2}{*}{ Texture } & Homogenous & 36 & $52.9 \%$ \\
& Heterogenous & 32 & $47.1 \%$ \\
\hline \multirow{2}{*}{ Echogenesity } & Hypo & 67 & $98.5 \%$ \\
& Isoechoic & 1 & $1.5 \%$ \\
\hline \multirow{2}{*}{ Onsite } & No & 65 & $95.6 \%$ \\
& Yes & 3 & $4.4 \%$ \\
\hline
\end{tabular}

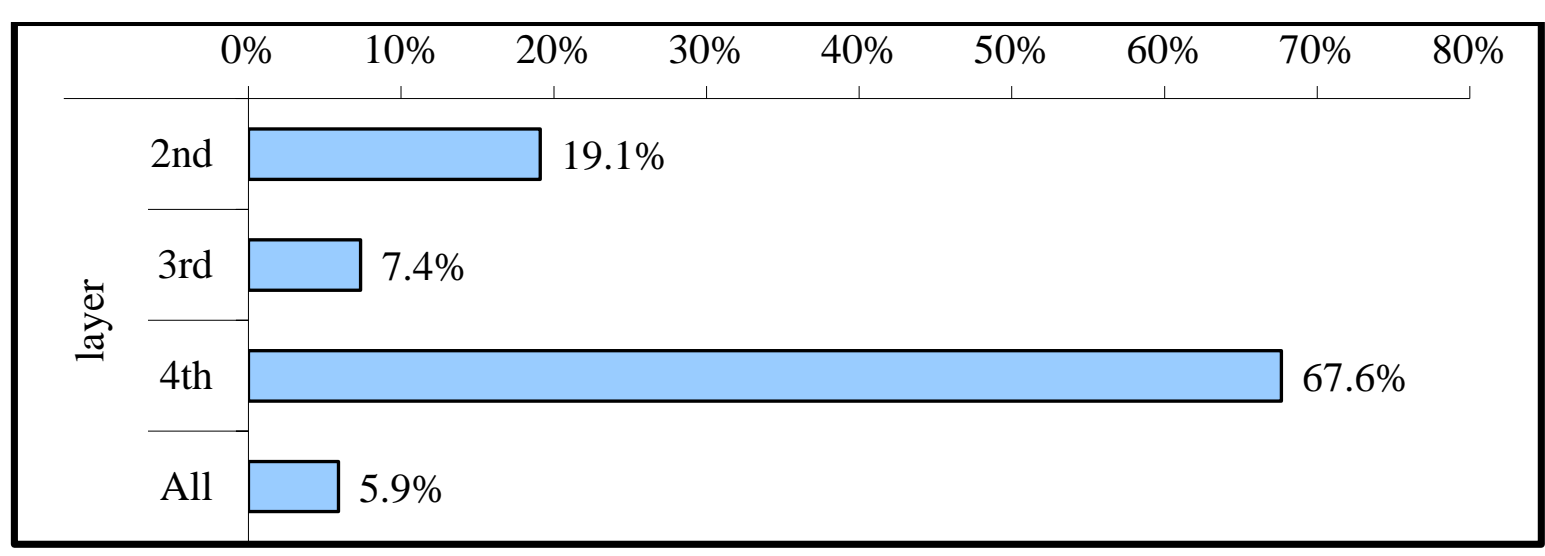

Fig. (3): The layers of GIT wall involved in GIST lesions

The results of EUS, EUS-FNA and the final diagnosis were categorized into 2 groups: malignant group and benign group. (Table 3 ).

- EUS diagnosis suggestive of malignant or benign GIST lesions was based on the affected layers and its echotexture. It was considered benign if any or all of the innermost three layers were affected (mucosa, muscularis mucosa, or submucosa), while it was considered malignant if the deeper muscularis propria layer (4th layer) was involved. Also, heterogeneous lesions were suggestive of malignancy while homogenous lesions suggested a benign nature of the lesion.

- EUS-FNA diagnosis (benign or malignant) was based on the presence or absence of malignant cells in cytological examination of the slides or the cell block.

- Final diagnosis was reached by postsurgical histopathological examination. 
Table (3): showing the number \& percentage of GIST lesions as diagnosed by EUS, EUS-FNA and final histopathology

\begin{tabular}{|l|l|l|l|}
\hline GIST & No. & $\%$ \\
\hline \multirow{2}{*}{ EUS diagnosis } & Malignant & 40 & $58.8 \%$ \\
& Benign & 28 & $41.2 \%$ \\
\hline \multirow{2}{*}{ Final Diagnosis } & Malignant & 39 & $57.4 \%$ \\
& Benign & 29 & $42.6 \%$ \\
\hline
\end{tabular}

Sensitivity and specificity of EUS in diagnosis of GIST lesions were $90.9 \%$ and $100 \%$ respectively. Positive predictive value (PPV) and negative predictive value (NPV) were 100\% and $85.7 \%$ respectively. Accuracy was 95.5 , while, sensitivity and specificity of EUS-FNA were $88.6 \%$ and $100 \%$ respectively. Positive predictive value (PPV) and negative predictive value (NPV) were $100 \%$ and $82.8 \%$ respectively. Accuracy was 92.6. (Table 4)

Table (4): sensitivity, specificity, accuracy, positive predictive value (PPV) and negative predictive value (NPV) for EUS and EUS-FNA diagnoses of GIST lesions in comparison to final histopathological diagnosis

\begin{tabular}{|l|c|c|c|c|c|}
\hline GIST & \multicolumn{5}{|c|}{ Final Diagnosis } \\
\hline Parameter & Accuracy & Sensitivity & Specificity & PPV & NPV \\
\hline EUS diagnosis & $\mathbf{9 5 . 5}$ & $90.9 \%$ & $100.0 \%$ & $100.0 \%$ & $\mathbf{8 5 . 7 \%}$ \\
\hline EUS FNA & $\mathbf{9 2 . 6}$ & $88.6 \%$ & $100.0 \%$ & $100.0 \%$ & $\mathbf{8 2 . 8 \%}$ \\
\hline
\end{tabular}

Malignant GIST lesions had positive correlation with certain factors which can be considered as predictors for malignant nature of the lesions; age, size of the lesion, Clinical presentation with dyspepsia and Heterogenous texture are significant predictors for malignancy. Gastric lesions originating in the body and fundus are more likely to be malignant than the cardia or the antrum, While, gender of the patients, site of the lesions, layer of origin, and echogenicity are non-significant factors in prediction of malignant nature. (Table 5)

Table (5): Showing correlation between different criteria as predictors of malignant cases and the final diagnosis of GIST lesions

\begin{tabular}{|c|c|c|c|c|c|c|}
\hline \multirow{3}{*}{\multicolumn{2}{|c|}{ GIST }} & \multicolumn{2}{|c|}{ Final Diagnosis } & \multirow{3}{*}{ Test value* } & \multirow{3}{*}{ P-value } & \multirow{3}{*}{ Sig. } \\
\hline & & \multirow{2}{*}{\begin{tabular}{|c|} 
Malignant \\
No. $=44$ \\
\end{tabular}} & \multirow{2}{*}{$\begin{array}{c}\text { Benign } \\
\text { No. }=24\end{array}$} & & & \\
\hline & & & & & & \\
\hline \multirow{2}{*}{ Age (years) } & Mean \pm SD & $55.95 \pm 8.20$ & $49.71 \pm 12.54$ & \multirow{2}{*}{$-2.479 \bullet$} & \multirow{2}{*}{0.016} & \multirow{2}{*}{$\mathbf{S}$} \\
\hline & Range & $37-75$ & $30-68$ & & & \\
\hline \multirow{2}{*}{ Gender } & Female & $16(36.4 \%)$ & $9(37.5 \%)$ & \multirow{2}{*}{$0.009 *$} & \multirow{2}{*}{0.926} & \multirow{2}{*}{ NS } \\
\hline & Male & $28(63.6 \%)$ & $15(62.5 \%)$ & & & \\
\hline \multirow{2}{*}{$\begin{array}{l}\text { Longest } \\
\text { dimension }(\mathrm{cm})\end{array}$} & Mean \pm SD & $5.42 \pm 2.51$ & $3.52 \pm 1.89$ & \multirow{2}{*}{$-3.228 \bullet$} & \multirow{2}{*}{0.002} & \multirow{2}{*}{ HS } \\
\hline & Range & $0.9-13$ & $1.20-10.70$ & & & \\
\hline \multirow{3}{*}{ Size group } & $\leq 2$ & $3(6.8 \%)$ & $4(16.7 \%)$ & \multirow{3}{*}{$15.823 *$} & \multirow{3}{*}{0.000} & \multirow{3}{*}{ HS } \\
\hline & $>2-\leq 5$ & $18(40.9 \%)$ & $19(79.2 \%)$ & & & \\
\hline & $>5$ & $23(52.3 \%)$ & $1(4.2 \%)$ & & & \\
\hline \multirow{3}{*}{ Presentation } & Dyspepsia & $20(45.5 \%)$ & $21(87.5 \%)$ & \multirow{3}{*}{$11.874 *$} & \multirow{3}{*}{0.003} & \multirow{3}{*}{ HS } \\
\hline & Bleeding & $9(20.5 \%)$ & $2(8.3 \%)$ & & & \\
\hline & Submucosal lesion & $15(34.1 \%)$ & $1(4.2 \%)$ & & & \\
\hline \multirow{5}{*}{ Site } & Gastric & $39(88.6 \%)$ & $18(75.0 \%)$ & \multirow{5}{*}{$9.693^{*}$} & \multirow{5}{*}{0.084} & \multirow{5}{*}{ NS } \\
\hline & Esophagus & $0(0.0 \%)$ & $4(16.7 \%)$ & & & \\
\hline & Rectum & $2(4.6 \%)$ & $1(4.2 \%)$ & & & \\
\hline & Duodenal & $2(4.5 \%)$ & $0(0.0 \%)$ & & & \\
\hline & $\begin{array}{l}\text { Gastroesophageal } \\
\text { junction }\end{array}$ & $1(2.3 \%)$ & $1(4.2 \%)$ & & & \\
\hline \multirow{4}{*}{ Gastric Type } & Fundus & $12(31.6 \%)$ & $8(47.1 \%)$ & \multirow{4}{*}{$9.543 *$} & \multirow{4}{*}{0.023} & \\
\hline & Body & $23(60.5 \%)$ & $4(23.5 \%)$ & & & \\
\hline & Cardia & $0(0.0 \%)$ & $2(11.8 \%)$ & & & $\mathbf{3}$ \\
\hline & Antrum & $3(7.9 \%)$ & $3(17.6 \%)$ & & & \\
\hline
\end{tabular}

P-value >0.05: Non significant (NS); P-value <0.05: Significant (S); P-value<0.01: highly significant (HS), *:Chi-square test 
Table 5 (cont.): Showing correlation between different criteria as predictors of malignant cases and the final diagnosis of GIST lesions

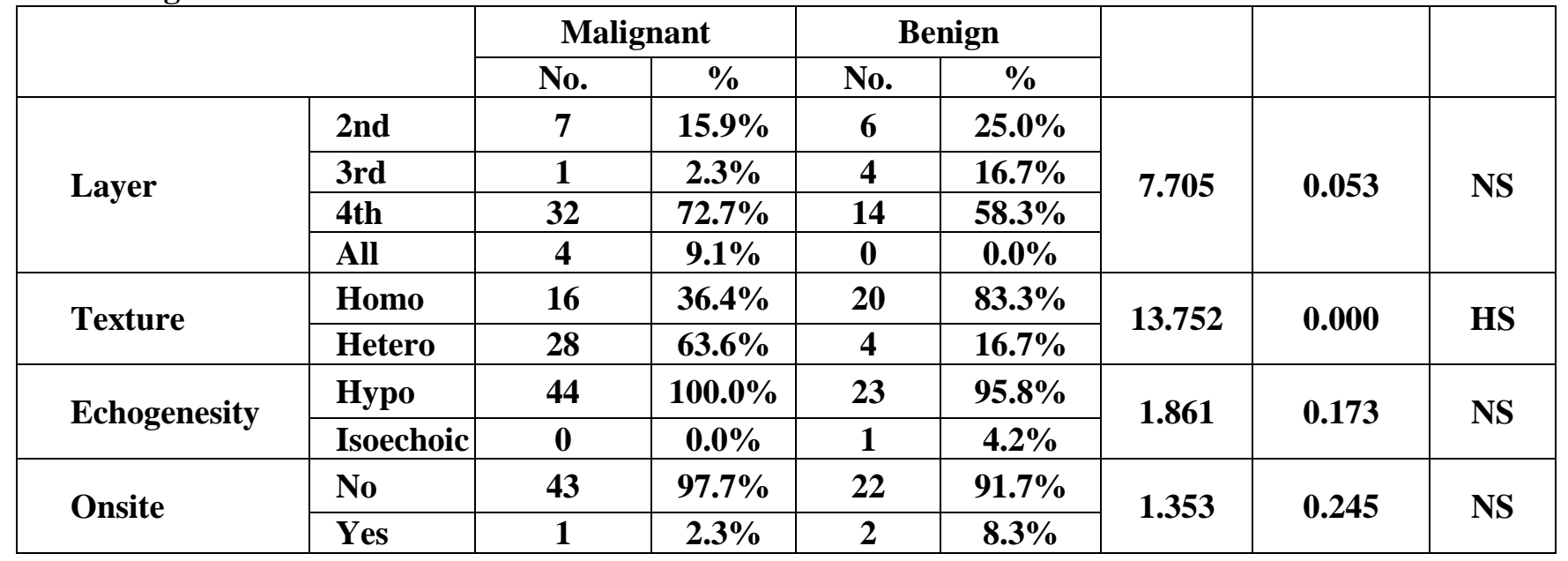

P-value >0.05: Non significant (NS); P-value <0.05: Significant (S); P-value< 0.01: highly significant (HS),

*:Chi-square test

Univariate and multivariate logistic regression analysis for predictors of malignant cases by final diagnosis which revealed that age of the patient, size of the lesion, clinical presentation and texture of the lesion are significant predictors of malignant behavior, while gastric site of the lesion is a non-significant predictor for malignancy (Tables 6,7 )

Table (6): Univariate logistic regression analysis for predictors of malignant cases by final diagnosis

\begin{tabular}{|c|c|c|c|c|c|c|c|}
\hline \multirow[t]{2}{*}{ 20. } & \multirow[b]{2}{*}{ B } & \multirow{2}{*}{ S.E. } & \multirow{2}{*}{ Wald } & \multirow{2}{*}{ P-value } & \multirow{2}{*}{$\begin{array}{c}\text { Odds } \\
\text { ratio } \\
(\text { OR })\end{array}$} & \multicolumn{2}{|c|}{ 95\% C.I. for OR } \\
\hline & & & & & & Lower & Upper \\
\hline Age & 0.063 & $\mathbf{0 . 0 2 7}$ & 5.306 & $0.021(S)$ & 1.065 & 1.009 & 1.123 \\
\hline $\begin{array}{l}\text { Longest } \\
\text { dimension }(\mathrm{cm})\end{array}$ & 0.460 & 0.162 & 8.091 & $0.004(\mathrm{HS})$ & 1.584 & 1.154 & 2.175 \\
\hline Size & 1.765 & 0.549 & 10.331 & 0.001(HS) & 5.843 & 1.991 & $\mathbf{1 7 . 1 4 6}$ \\
\hline Presentation & 1.428 & 0.486 & 8.632 & $0.003(S)$ & 4.171 & 1.609 & 10.816 \\
\hline Gastric Type & -0.186 & 0.314 & 0.352 & $0.553(\mathrm{NS})$ & 0.830 & 0.449 & 1.536 \\
\hline Texture & 2.169 & 0.631 & 11.815 & $0.001(\mathrm{HS})$ & 8.75 & 2.54 & 30.141 \\
\hline
\end{tabular}

CI: confidence interval; OR: odds ratio

Table (7): Multivariate logistic regression analysis for predictors of malignant cases by final diagnosis

\begin{tabular}{|c|c|c|c|c|c|c|c|}
\hline & \multirow{2}{*}{ B } & \multirow{2}{*}{ S.E. } & \multirow{2}{*}{ Wald } & \multirow{2}{*}{ P-value } & \multirow{2}{*}{$\begin{array}{c}\text { Odds } \\
\text { ratio }(\mathrm{OR})\end{array}$} & \multicolumn{2}{|c|}{ 95\% C.I. for OR } \\
\hline & & & & & & Lower & Upper \\
\hline Age & 0.041 & 0.057 & 0.503 & 0.478 & 1.041 & 0.931 & 1.165 \\
\hline $\begin{array}{l}\text { Longest } \\
\text { dimension }(\mathrm{cm})\end{array}$ & -1.371 & 1.703 & 0.649 & 0.421 & 0.254 & 0.009 & 7.139 \\
\hline Size & 8.828 & 6.369 & 1.921 & 0.166 & 21.003 & 0.026 & 179.282 \\
\hline presentation & 6.027 & 3.009 & 4.011 & 0.045 & 14.344 & 1.137 & 150.784 \\
\hline Gastric type & -1.127 & 1.016 & 1.230 & 0.267 & 0.324 & 0.044 & 2.373 \\
\hline Texture & 5.956 & 3.114 & 3.659 & 0.056 & 36.114 & 0.863 & 172.172 \\
\hline Constant & -28.127 & 14.263 & 3.889 & 0.049 & 0.000 & & \\
\hline
\end{tabular}

CI: confidence interval; OR: odds ratio 


\section{DISCUSSION}

This was a prospective study conducted to evaluate EUS and EUS-FNA as diagnostic tools of GIST lesions of the gastrointestinal tract, including 150 cases presented with submucosal lesions for further EUS-FNA evaluation of which the most common encountered lesion was GIST 68(45.3\%) lesions.

Gastrointestinal stromal tumors are the most common mesenchymal neoplasms of the GI tract. The incidence of GISTs is estimated at around 10 to 20 per 1 million people. Around $90 \%$ of cases are diagnosed in patients older than 40 years, with a median age of 63 years. Most patients are symptomatic at presentation $(70 \%-90 \%){ }^{(11,12)}$.

GISTs mainly affect the stomach (around 60\%) and small intestine (around 30\%), and rarely affect the colon (around 5\%), esophagus (2\%-4\%), and appendix $(<2 \%)$. Extra-gastrointestinal GISTs have been reported ${ }^{(13)}$.

In our study there were 68 GIST lesions including 43(63.2\%) males and 25(36.8\%) females. The mean age was $54 \pm 10.3$ years. These results were in agreement with Lauren and Carlo ${ }^{(14)}$.

Most of the GIST patients $41(60.3 \%)$ were presented with dyspepsia while $16(23.5 \%)$ were presented with submucosal lesions accidentally discovered during conventional GIT endoscopy.

This data was in agreement with Sandvik et al. (15) and Manrique et al. ${ }^{(16)}$ who roughly classified their study patients into symptomatic and incidental (asymptomatic or accidentally discovered).

The majority of cases were gastric 57(83.8\%), this was in agreement with Søreide et al. ${ }^{(17)}$ most of which were in the gastric body $27(47.3 \%) .{ }^{12} \mathrm{Also}$, Chiang et al (2014) reported that most of cases of his study were gastric (55.6\%) followed by small intestinal (31.8\%).

The GIST lesions were classified according to size into: $7(10.3 \%)$ cases were $\leq 2 \mathrm{~cm}, 37(54.4 \%)$ cases were $(>2-\leq 5) \mathrm{cm}$ and $24(35.3 \%)$ cases were $>5 \mathrm{~cm}$ in maximum diameter and the majority of cases were $(>2-\leq 5) \mathrm{cm}$.

This data was in agreement with Cho et al. ${ }^{(18)}$ who found that $30 \%$ of lesions were $\leq 2 \mathrm{~cm}, 43 \%$ were (>2- $\leq 5)$ and $27 \%$ were $>5$, while Sandvik $\boldsymbol{e t}$ al. ${ }^{(15)}$ who found that most of cases were $>5 \mathrm{~cm}$ (45\%), while $28 \%$ of lesions were $\leq 2 \mathrm{~cm}$ and $27 \%$ were $(>2-\leq 5)$.

Our results indicated that the specificity of EUS-FNA diagnosis of GIST lesions $100 \%$ with an overall sensitivity of $88.6 \%$. Positive predictive value (PPV) was $100 \%$, while negative predictive value (NPV) was $82.8 \%$. Accuracy was $92.6 \%$.

Several factors that may impact the diagnostic yield of EUS-FNA of SMLs have been evaluated, including lesion size, type and size of needle used, biopsy technique, the availability of on-site cytology review, and whether or not a stylet or suction are used. The diagnostic yield for EUSFNA in small lesions is low, thus, various other endoscopic techniques described earlier have been used to obtain tissue for histologic evaluation ${ }^{(\mathbf{1 9})}$.

Our study indicated that malignant GIST lesions had positive correlation with certain factors; age is a significant predictor for malignancy. Also, gastric lesions originating in the body and fundus are more likely to be malignant than the cardia or the antrum.

Our study shows that the size of the lesion, clinical presentation with dyspepsia and heterogenous texture of lesions were highly significant predictors for malignant nature.

This was consistent with Humphris and Jones ${ }^{(20)}$ who reported that risk of malignancy depends on the size, the number of cells at pathological evaluation and location.

While, in our study, gender of the patients, site of the lesions, layer of origin, and echogenicity, are non-significant factors in the prediction of malignant nature. In contrast to Huang et al. ${ }^{(21)}$ who found that small intestinal GISTs tend to be more aggressive than gastric GISTs.

This study revealed that EUS and EUS-FNA were highly significant methods in diagnosis of SMLs in relation to final histopathological diagnosis.

Dias et al. ${ }^{(10)}$ concluded that EUS is the method of choice in the study of submucosal lesions of the upper gastrointestinal tract, in most cases defining a diagnosis.

\section{CONCLUSION AND RECOMMENDATION}

It could be concluded that EUS-FNA with 22gauge needles is an accurate and safe method with a reliable sensitivity and specificity for diagnosing GIST lesions. Routine practice with onsite cytopathological examination helps to reach more accurate diagnosis. Additional immunohistochemical (IHC) examination of the obtained specimens will make diagnosis more optimal.

Based our results, we recommend a short algorithmic approach for the diagnosis of GIST lesions. An initial EUS can rule out extraluminal, hyperechoic, and third-layer (submucosal) lesions. For hypoechoic lesions that originate from the fourth (muscle) layers, EUS-FNA should be performed even for small lesions, and IHC stains with a panel of CD34, c-kit, actin, and S-100 should be done if spindle cells are found. 
Conflicts of interest: no conflicts of interest were encountered.

\section{REFERENCES}

1. Rejeski JJ, Girish Mishra (2018): Endoscopic ultrasound-guided tissue acquisition of subepithelial masses. Techniques in Gastrointestinal Endoscopy, 20: $15-20$.

2. Gress F, Savides $\mathbf{T}$ (2009): Endoscopic Ultrasonography. Oxford, UK: Wiley-Blackwell. Pp. 216. https://www.wiley.com/enus/Endoscopic+Ultrasonography $\% 2 \mathrm{C}+2 \mathrm{nd}+$ Edition-p-9781444359992

3. Baysal B, Masri OA, Eloubeidi MA et al. (2017): The role of EUS and EUS-guided FNA in the management of subepitheliallesions of the esophagus: alarge, single-center experience. Endosc Ultrasound, 6:308-16.

4. Karaca C, Brian GT, Sevdenur C et al. (2010): Accuracy of EUS in the evaluation of small gastric subepithelial lesions Original Research Article. Gastrointestinal Endoscopy, 71(4): 722-727.

5. Omar S, Manoop SB, Kenjiro Y et al. (2013): Clinical controversies in endoscopic ultrasound. Gastroenterol Rep (Oxf), 1(1):33-41.

6. Mohamad AE, Decker GA, Chandrasekhara V et al. (2007): The role of endoscopy in the evaluation and management of patients with solid pancreatic neoplasia. Gastrointestinal Endoscopy, 66: 425-34.

7. Yoshinaga S, Ichiro O, Satoru N et al. (2012): Endoscopic ultrasound using ultrasound probes for the diagnosis of early esophageal and gastric cancers. World J Gastrointest Endosc., 4(6): 218-226.

8. Wani S, Muthusamy VR, Komanduri S (2014): EUS-guided tissue acquisition: an evidence-based approach (with videos): Gastrointest Endosc., 80:939-959.

9. Sepe PS, Brugge WR (2009): A guide for the diagnosis and management of gastrointestinal stromal cell tumors. Nat Rev Gastroenterol Hepatol., 6:363-71.

10. Castro DFD, Magalhães $\mathrm{J}$, Monteiro $\mathrm{S}$ et al. (2016): The Role of Endoscopic Ultrasound in the Diagnostic Assessment of Subepithelial Lesions of the Upper Gastrointestinal Tract GE Port J Gastroenterol., 23(6):287- 292.
11. Stamatakos M, Douzinas E, Stefanaki C et al. (2009): Gastrointestinal stromal tumor. World J Surg Oncol., 7:61-6.

12. Soreide K, Sandvik OM, Soreide JA et al. (2016): Global epidemiology of gastrointestinal stromal tumours (GIST): A systematic review of populationbased cohort studies. Cancer Epidemiol., 40:39-46.

13. Petrou A, Alexandrou P, Papalambros A et al. (2011): A malignant gastrointestinal stromal tumor of the gallbladder immunoreactive for PDGFRA and negative for CD 117 Antigen (c-KIT). HPB Surgery, 2011(4):327192.

14. Lauren T, Carlo M (2019): Gastrointestinal Stromal Tumors of the Stomach and Esophagus. Surg Clin N Am, 99, 543-553. Global epidemiology of gastrointestinal stromal tumours (GIST): A systematic review of population-based cohort studies. Surg Clin North Am., 99(3):543-553.

15. Sandvik OM, Søreide K, Kvaløy JT et al. (2011): Epidemiology of gastrointestinal stromal tumours: single-institution experience and clinical presentation over three decades, Cancer Epidemiol., 35: 515-520.

16. Manrique MN, Soriano C, Yabar A et al. (2012): Gastrointestinal stromal tumors: clinicopathologic and survival evaluation in Rebagliati Rev Gastroenterol Peru., 32(4):357-65.

17. Chiang NJ, Chen LT, Tsai CR et al. (2014): The epidemiology of gastrointestinal stromal tumors in Taiwan, 1998-2008: a nation-wide cancer registrybased study. BMC Cancer, 14: 102-5.

18. Cho MY, Sohn JH, Kim JM et al. (2010): Current trends in the epidemiological and pathological characteristics of gastrointestinal stromal tumors in Korea, 2003-2004. J Korean Med Sci., 25: 853-862.

19. Faulx AL, Kothari S, Acosta RD et al. (2017): The role of endoscopy in subepitheliallesions of th eGI tract. Gastrointest Endosc., 85:1117-32.

20. Humphris JL, Jones DB (2008): Subepithelial mass lesions in the upper gastrointestinal tract. J Gastroenterol Hepatol., 23: 556-66.

21. Huang Y, Chen G, Lin L et al. (2019): Resection of GIST in the duodenum and proximal jejunum: A retrospective analysis of outcomes, European Journal of Surgical Oncology, 10: 1950-1956. 